OPEN ACCESS

Edited by:

Richard Gary Trohman,

Rush University, United States

Reviewed by:

Dorota Zyśko,

Wroclaw Medical University, Poland Vasilios E. Papaioannou,

Democritus University of Thrace,

Greece

*Correspondence:

Xiang-Lan Li

Ixianglanf@163.com

Jian-Qin Liang

wliangjianqin@126.com

tThese authors have contributed equally to this work

Specialty section:

This article was submitted to Respiratory Physiology, a section of the journal Frontiers in Physiology

Received: 13 December 2021 Accepted: 31 January 2022 Published: 08 March 2022

Citation:

An $\mathrm{H}-\mathrm{R}$, Han $\mathrm{Y}-\mathrm{R}$, Wang $\mathrm{T}-\mathrm{H}$, Chi F, Meng $Y$, Zhang $C-Y$, Liang J-Q and $L i$

$X-L$ (2022) Meta-Analysis of the Factors Influencing the Restoration of Spontaneous Circulation After Cardiopulmonary Resuscitation.

Front. Physiol. 13:834352.

doi: 10.3389/fphys.2022.834352

\section{Meta-Analysis of the Factors Influencing the Restoration of Spontaneous Circulation After Cardiopulmonary Resuscitation}

\author{
Hui-Ru An ${ }^{1 \dagger}$, Yi-Ran Han ${ }^{1 \dagger}$, Tian-Hao Wang $^{2 t}$, Fei Chi ${ }^{3}$, Yu Meng ${ }^{3}$, Chun-Yan Zhang ${ }^{3}$, \\ Jian-Qin Liang ${ }^{1 *}$ and Xiang-Lan $L^{3 *}$ \\ 'Department of Tuberculosis, Senior Department of Tuberculosis, The Eighth Medical Center of PLA General Hospital, \\ Beijing, China, ${ }^{2} E m e r g e n c y$ Department, The Eighth Medical Center of PLA General Hospital, Beijing, China, ${ }^{3} E m e r g e n c y$ \\ Department, Hebei Chest Hospital, Shijiazhuang City, China
}

Objective: This study aimed to systematically evaluate the factors influencing the restoration of spontaneous circulation (ROSC) after cardiopulmonary arrest (CA).

Methods: Relevant papers on the factors influencing the ROSC in patients with CA were retrieved from PubMed, Embase, Cochrane Library, China Biology Medicine disk, China National Knowledge Infrastructure, Wanfang, and VIP databases. After screening, data extraction, and quality evaluation of the papers, a meta-analysis was carried out.

Results: A total of 36 papers, involving a total sample size of 2,305 cases, were included. The meta-analysis revealed that the location and time of onset of CA, the type of cardiac rhythm at first monitoring, the start time of cardiopulmonary resuscitation (CPR), the use of electric defibrillation, and the cumulative dose of adrenaline all significantly impacted the ROSC $(p<0.05)$ and may have affected its success rate. The $\mathrm{pH}$ value at CA onset, combined use of adrenaline and vasopressin, CPR duration, mechanical cardiac compression use, and whether CA was caused by heart disease had no significant effect on ROSC.

Conclusion: The location and time of onset of CA, the cardiac rhythm at first monitoring, the start time of CPR, the use of electric defibrillation, and the cumulative dose of adrenaline significantly impacted the ROSC.

Keywords: cardiopulmonary resuscitation, return of spontaneous circulation, influencing factors, meta-analysis, cardiopulmonary arrest

\section{INTRODUCTION}

Cardiopulmonary arrest (CA) is a common acute and critical illness in which the heartbeat ceases without warning and the patient suddenly stops breathing. There is a sudden loss of consciousness, respiratory arrest, or weak, sigh-like breathing, and no pulse can be felt. Cardiopulmonary resuscitation (CPR) is an important measure used to treat CA. Although $\mathrm{CPR}$ and other advanced recovery technologies are improving, the restoration of spontaneous 
circulation (ROSC) rate is still very low (Tang et al., 2017). This study systematically evaluated the factors influencing the ROSC in patients with CA to provide a reference point for future treatment.

\section{MATERIALS AND METHODS}

\section{Literature Retrieval}

Relevant studies, published between 1 January 2010, and 1 January 2021, were retrieved from databases including PubMed, Embase, the China Biology Medicine disk, the China National Knowledge Infrastructure, and the Wanfang, and VIP databases. The English keywords were "cardiovascular resuscitation," "diagnostic factors," "cardiac arrest," and "factors analysis.” The Chinese keywords were “心肺复苏, “心脏骤 停,” “心搏骤停,” and “预后,” In addition, the references of all the included papers were retrieved to identify more relevant studies. All documents were entered onto the Endnote reference management software. Two researchers independently screened the papers to evaluate the eligibility of the studies and were blinded to each other's decisions. Standard data extraction tables were used to extract data and to crosscheck the results to minimize bias and randomization errors in the data analysis.

\section{Inclusion and Exclusion Criteria}

Inclusion criteria: (1) All the included patients were diagnosed with CA in emergency departments; (2) all patients underwent CPR; (3) all studies were of a randomized controlled, case-control, or cohort design; and (4) complete data were available.

Exclusion criteria: (1) The full text or quantitative extraction of indicators was not available; (2) the paper was a review, a case report, an animal study, or nursing-related or in vitro research; (3) the paper was a duplicate or of a low quality; and (4) the language was not Chinese or English.

\section{Data Extraction and Quality Evaluation}

For each paper, the first author, year of publication, country or region of publication, sample size, gender, age, clinical indicators, and other patient-related data were extracted. The quality of the cohort studies was evaluated by two researchers in strict accordance with the Newcastle-Ottawa Scale (NOS). Where there was disagreement, this was discussed by both parties or ruled upon by a third researcher.

\section{Statistical Analysis}

The data were statistically analyzed using the statistical software STATA 11.0. Cochran's Q test and the $I^{2}$ test were used to test for heterogeneity. If $p<0.05$ or $I^{2}>50 \%$, the random effect model was adopted, and if $p>0.05$ or $I^{2}<50 \%$, the fixed-effects model was adopted. The risk ratio (RR) and a 95\% CI were used to evaluate the therapeutic effect of binary variables. Standardized mean difference (SMD) or weighted mean difference (WMD) was used to analyze continuous variables according to whether the units of specific indicators were unified. The inspection level of the metaanalysis was set as $\alpha=0.05$, and the $95 \%$ CI was calculated for all analyses. Egger's test was used to evaluate publication bias, while evaluation quality bias was eliminated by a sensitivity analysis.

\section{RESULTS}

\section{Characteristics of the Selected Studies}

A total of 10,202 papers were retrieved. After excluding duplicate and irrelevant papers, a total of 36 studies, based on 2,305 patients, were included. The literature retrieval flow chart is shown in Figure 1. The characteristics of the included papers are shown in Table 1 . The results of the evaluation of the study quality, according to the NOS scale, are shown in Figure 2.

\section{Meta-Analysis Results}

Meta-Analysis of the Impact of Location and Time of Onset of CA on the ROSC

Eight and 10 articles, respectively, investigated these relationships (Figures 3A,B). The meta-analysis revealed that, compared with out-of-hospital CA, the RR for the ROSC in the hospital was 3.59 (95\% CI $=2.05-6.28, p<0.001)$, and compared with $\mathrm{CA}$ at night, the RR for the ROSC during the day was 1.40 (95\% CI $=1.25-1.57, p<0.001)$. Therefore, both the location and time of CA are associated with the success rate of the ROSC.

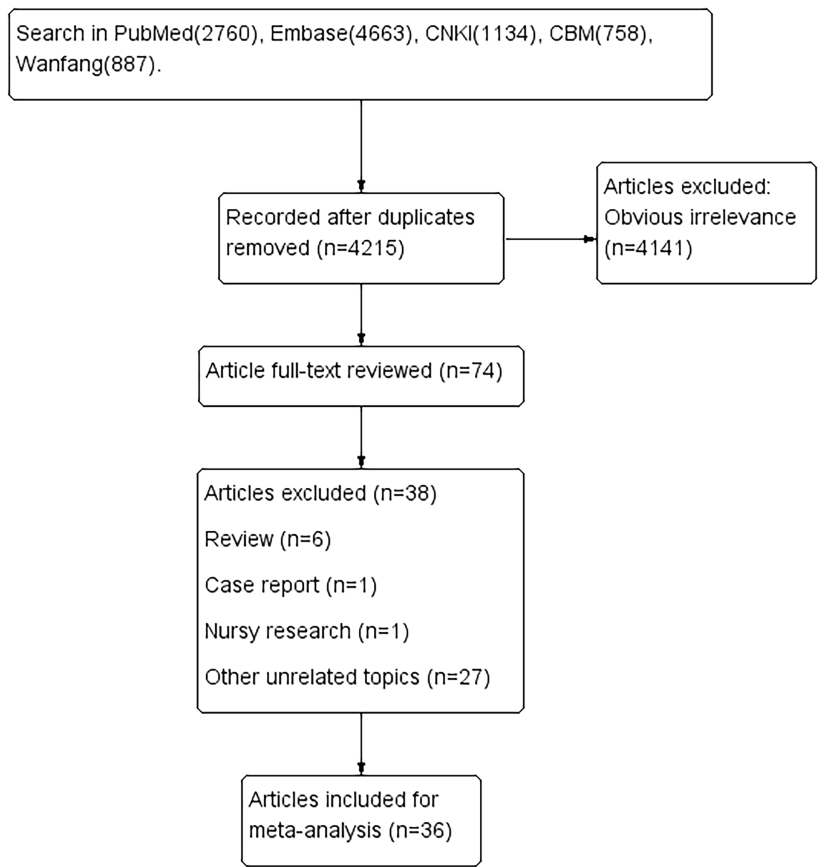

FIGURE 1 | The literature retrieval flow chart. 
TABLE 1 | Basic situations of included literatures.

\begin{tabular}{|c|c|c|c|c|c|c|c|c|c|c|c|}
\hline \multirow[b]{2}{*}{ References } & \multicolumn{2}{|c|}{ Sample size } & \multicolumn{3}{|c|}{ Age } & \multicolumn{2}{|c|}{ Gender } & \multirow[b]{2}{*}{ State } & \multirow[b]{2}{*}{$\begin{array}{l}\text { Literature } \\
\text { type }\end{array}$} & \multirow[b]{2}{*}{$\begin{array}{l}\text { NOS } \\
\text { score }\end{array}$} & \multirow[b]{2}{*}{$\begin{array}{l}\text { Outcome } \\
\text { indicator }\end{array}$} \\
\hline & $\begin{array}{l}\text { Control } \\
\text { group }\end{array}$ & $\begin{array}{l}\text { Observation } \\
\text { group }\end{array}$ & $\begin{array}{l}\text { Control } \\
\text { group }\end{array}$ & $\begin{array}{l}\text { Observation } \\
\text { group }\end{array}$ & $\begin{array}{l}\text { Average } \\
\text { age }\end{array}$ & Male & Female & & & & \\
\hline $\begin{array}{l}\text { Dumas } \\
\text { et al., } 2014\end{array}$ & 1,134 & 422 & 60.3 & 58.3 & NA & 1,112 & 444 & France & CS & 8 & (10) \\
\hline $\begin{array}{l}\text { Xue et al., } \\
2013\end{array}$ & 187 & 538 & NA & NA & NA & 519 & 206 & China & CS & 6 & (1)(2)(3)(4)(7)(10) \\
\hline $\begin{array}{l}\text { Ducros } \\
\text { et al., } 2011\end{array}$ & 16 & 14 & $60 \pm 4$ & $56 \pm 4$ & NA & 25 & 5 & France & $\mathrm{RCT}$ & 0 & (10) \\
\hline $\begin{array}{l}\text { Ong et al., } \\
2012\end{array}$ & 353 & 374 & 64.9 & 64.6 & NA & 505 & 222 & Singapore & $\mathrm{RCT}$ & 0 & (10) \\
\hline $\begin{array}{l}\text { Rohlin et al., } \\
2018\end{array}$ & 1,639 & 798 & NA & NA & NA & 145 & 103 & Sweden & CS & 8 & (7) \\
\hline $\begin{array}{l}\text { Takayama } \\
\text { et al., } 2019\end{array}$ & 948 & 306 & 72 & 67 & NA & 837 & 417 & Japan & CS & 8 & (2) \\
\hline Cai, 2020 & 39 & 61 & $72.1 \pm 13.25$ & $45.2 \pm 11.23$ & NA & 23 & 16 & China & CS & 5 & (3)(4) \\
\hline $\begin{array}{l}\text { Ding and } \\
\text { Xie, } 2012\end{array}$ & 82 & 72 & NA & NA & NA & 98 & 56 & China & CS & 8 & (5) \\
\hline $\begin{array}{l}\text { Qiao et al., } \\
2016\end{array}$ & 77 & 71 & NA & NA & NA & 85 & 63 & China & $\mathrm{CS}$ & 5 & (5) \\
\hline Liu, 2018 & 125 & 75 & NA & NA & NA & 137 & 63 & China & $\mathrm{CS}$ & 7 & (1)(7)8(10) \\
\hline Mao, 2019 & 147 & 71 & 51 & 73 & NA & 143 & 75 & China & CS & 5 & \\
\hline $\begin{array}{l}\text { Zhou et al., } \\
2020\end{array}$ & 71 & 27 & NA & NA & NA & 58 & 40 & China & $\mathrm{CS}$ & 6 & (3)(910) \\
\hline $\begin{array}{l}\text { Zhang et al., } \\
2021 a\end{array}$ & 40 & 28 & NA & NA & NA & 39 & 29 & China & $\mathrm{CS}$ & 5 & (3)(5)(10) \\
\hline $\begin{array}{l}\text { Zhang et al., } \\
2018\end{array}$ & 36 & 57 & $71.33 \pm 8.25$ & $72.45 \pm 7.64$ & NA & 51 & 42 & China & $\mathrm{CS}$ & 6 & (3)(6)(7)(10) \\
\hline $\begin{array}{l}\text { Zhang et al., } \\
2021 b\end{array}$ & 38 & 114 & NA & NA & $51.43 \pm 15.29$ & 27 & 11 & China & CS & 7 & (1)(2)(4)6(10) \\
\hline $\begin{array}{l}\text { Zhang, } \\
2020\end{array}$ & 100 & 100 & $70.4 \pm 6.48$ & $51.2 \pm 6.11$ & NA & 58 & 42 & China & $\mathrm{CS}$ & 5 & \\
\hline $\begin{array}{l}\text { Xu et al., } \\
2019\end{array}$ & 861 & 530 & NA & NA & $60.1 \pm 18.9$ & 821 & 570 & China & $\mathrm{CS}$ & 5 & (2)(3)(4)(78)(10) \\
\hline $\begin{array}{l}\text { Jing et al., } \\
2017\end{array}$ & 72 & 321 & $65.6 \pm 17.32$ & $65.0 \pm 16.43$ & NA & 284 & 109 & China & CS & 5 & (1) \\
\hline Li, 2017 & 37 & 21 & NA & NA & $45.27 \pm 6.18$ & 31 & 27 & China & CS & 3 & \\
\hline $\begin{array}{l}\text { Li et al., } \\
2018 a\end{array}$ & 55 & 31 & NA & NA & NA & 49 & 37 & China & CS & 4 & \\
\hline Li, 2020 & 46 & 74 & NA & NA & $66.5 \pm 6.6$ & 72 & 48 & China & CS & 7 & (1)(2) (3) (4) (6)(7) (10) \\
\hline $\begin{array}{l}\text { Li and Jia, } \\
2020\end{array}$ & 50 & 53 & $54.1 \pm 10.37$ & $53.7 \pm 11.25$ & NA & 56 & 47 & China & CS & 5 & (10) \\
\hline Du, 2014 & 9 & 51 & NA & NA & $46.8 \pm 9.7$ & 37 & 23 & China & CS & 5 & \\
\hline $\begin{array}{l}\text { Yang et al., } \\
2016\end{array}$ & 75 & 223 & NA & NA & NA & 205 & 93 & China & CS & 5 & (2)(3)(4)(10) \\
\hline $\begin{array}{l}\text { Hu et al., } \\
2018\end{array}$ & 208 & 405 & NA & NA & $59.42 \pm 18.61$ & 410 & 203 & China & CS & 8 & (5) \\
\hline $\begin{array}{l}\text { Hu and Lu, } \\
2016\end{array}$ & 129 & 152 & NA & NA & NA & 161 & 120 & China & CS & 8 & (2) 5 \\
\hline $\begin{array}{l}\text { Cai et al., } \\
2019\end{array}$ & 81 & 71 & NA & NA & $65.33 \pm 14.98$ & 96 & 56 & China & CS & 8 & (2) 8 \\
\hline $\begin{array}{l}\text { Chen and } \\
\text { Luo, } 2018\end{array}$ & 48 & 56 & NA & NA & NA & 71 & 33 & China & CS & 5 & (2)(7)(10) \\
\hline $\begin{array}{l}\text { Chen et al., } \\
2020\end{array}$ & 71 & 31 & NA & NA & $69.9 \pm 17.7$ & 57 & 45 & China & CS & 7 & (1)(3)6(7) \\
\hline Chen, 2019 & 18 & 64 & NA & NA & $56.17 \pm 8.11$ & 50 & 32 & China & CS & 7 & \\
\hline $\begin{array}{l}\text { Chen et al., } \\
2016\end{array}$ & 29 & 105 & NA & NA & NA & 92 & 42 & China & CS & 5 & \\
\hline Wei, 2021 & 16 & 104 & NA & NA & $60.2 \pm 10.4$ & 83 & 37 & China & CS & 5 & (1)(2)(3)(4)(10) \\
\hline $\begin{array}{l}\text { Li et al., } \\
2018 b\end{array}$ & 39 & 185 & $61.3 \pm 13.4$ & $60.3 \pm 12.8$ & NA & 140 & 84 & China & CS & 5 & (2)(10) \\
\hline $\begin{array}{l}\text { Zhao et al., } \\
2021\end{array}$ & 41 & 41 & $44.89 \pm 6.92$ & $46.31 \pm 7.86$ & NA & 50 & 32 & China & $\mathrm{CS}$ & 6 & (9) \\
\hline
\end{tabular}


TABLE 1 | Continued

\begin{tabular}{|c|c|c|c|c|c|c|c|c|c|c|c|}
\hline \multirow[b]{2}{*}{ References } & \multicolumn{2}{|c|}{ Sample size } & \multicolumn{3}{|c|}{ Age } & \multicolumn{2}{|c|}{ Gender } & \multirow[b]{2}{*}{ State } & \multirow[b]{2}{*}{$\begin{array}{l}\text { Literature } \\
\text { type }\end{array}$} & \multirow[b]{2}{*}{$\begin{array}{l}\text { NOS } \\
\text { score }\end{array}$} & \multirow[b]{2}{*}{$\begin{array}{l}\text { Outcome } \\
\text { indicator }\end{array}$} \\
\hline & $\begin{array}{l}\text { Control } \\
\text { group }\end{array}$ & $\begin{array}{l}\text { Observation } \\
\text { group }\end{array}$ & $\begin{array}{l}\text { Control } \\
\text { group }\end{array}$ & $\begin{array}{l}\text { Observation } \\
\text { group }\end{array}$ & $\begin{array}{c}\text { Average } \\
\text { age }\end{array}$ & Male & Female & & & & \\
\hline $\begin{array}{l}\text { Ding and } \\
\text { Zhang, } \\
2018\end{array}$ & 32 & 32 & $45.63 \pm 2.58$ & $46.85 \pm 3.15$ & NA & 37 & 27 & China & CS & 6 & (9) \\
\hline $\begin{array}{l}\text { Zhu et al., } \\
2016\end{array}$ & 49 & 49 & $36.4 \pm 5.7$ & $40.3 \pm 3.4$ & NA & 50 & 48 & China & CS & 4 & (9) \\
\hline
\end{tabular}

(1) Impact of CA onset location on ROSC; (2) impact of CA onset time on ROSC; (3) impact of whether cardiogenic CA on ROSC; (4) impact of whether defibrillable rhythm on ROSC; (5) impact of pH on ROSC in patients with CA; (6) impact of CPR start time on ROSC; (7) impact of CPR duration on ROSC; (8) impact of whether electrical defibrillation on ROSC in patients with CA; (9) impact of whether CPR machine is used on ROSC in patients with CA; (10 impact of cumulative dose of adrenaline on ROSC in patients with CA; and (10) impact of combination of adrenaline and vasopressin on ROSC in patients with CA.

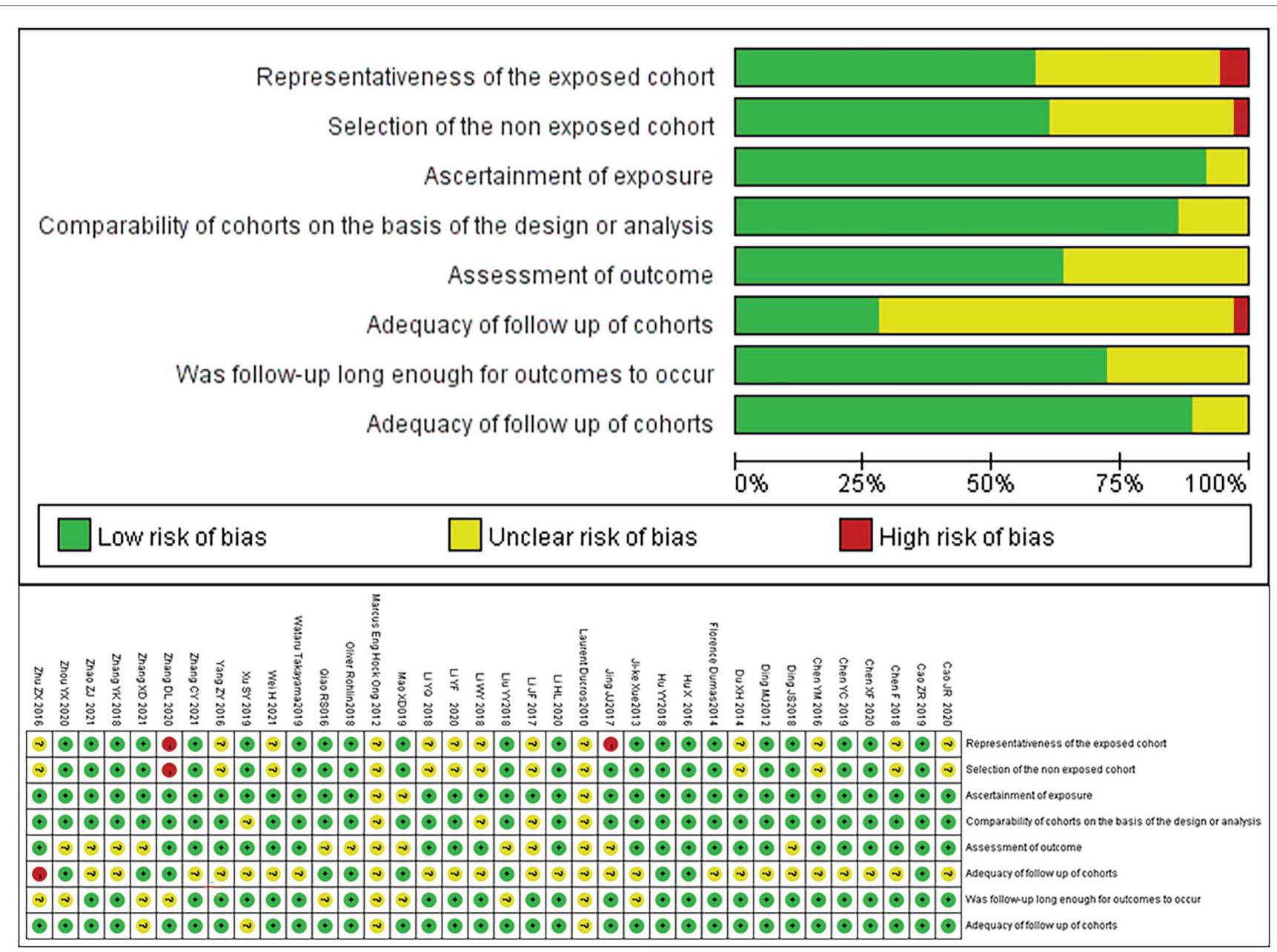

FIGURE 2 | The quality evaluation of the included studies.

\section{Meta-Analysis of the Type of CA and Rhythm, and $\mathrm{pH}$ Value Before Treatment, on the ROSC}

Nine, 13, and four papers, respectively, explored the relationships between these factors and the ROSC. Cardiac CA refers to $\mathrm{CA}$ that is caused by heart disease, non-cardiac CA refers to
CA that is not caused by heart disease. Compared with patients with cardiac CA, the RR for the ROSC in patients with non-cardiac CA was $0.88 \quad(95 \% \quad \mathrm{CI}=0.74-1.05, \quad p=0.167$; Figure 4A). Compared with patients whose heart rhythm was not amenable to direct current cardioversion/defibrillation, the 

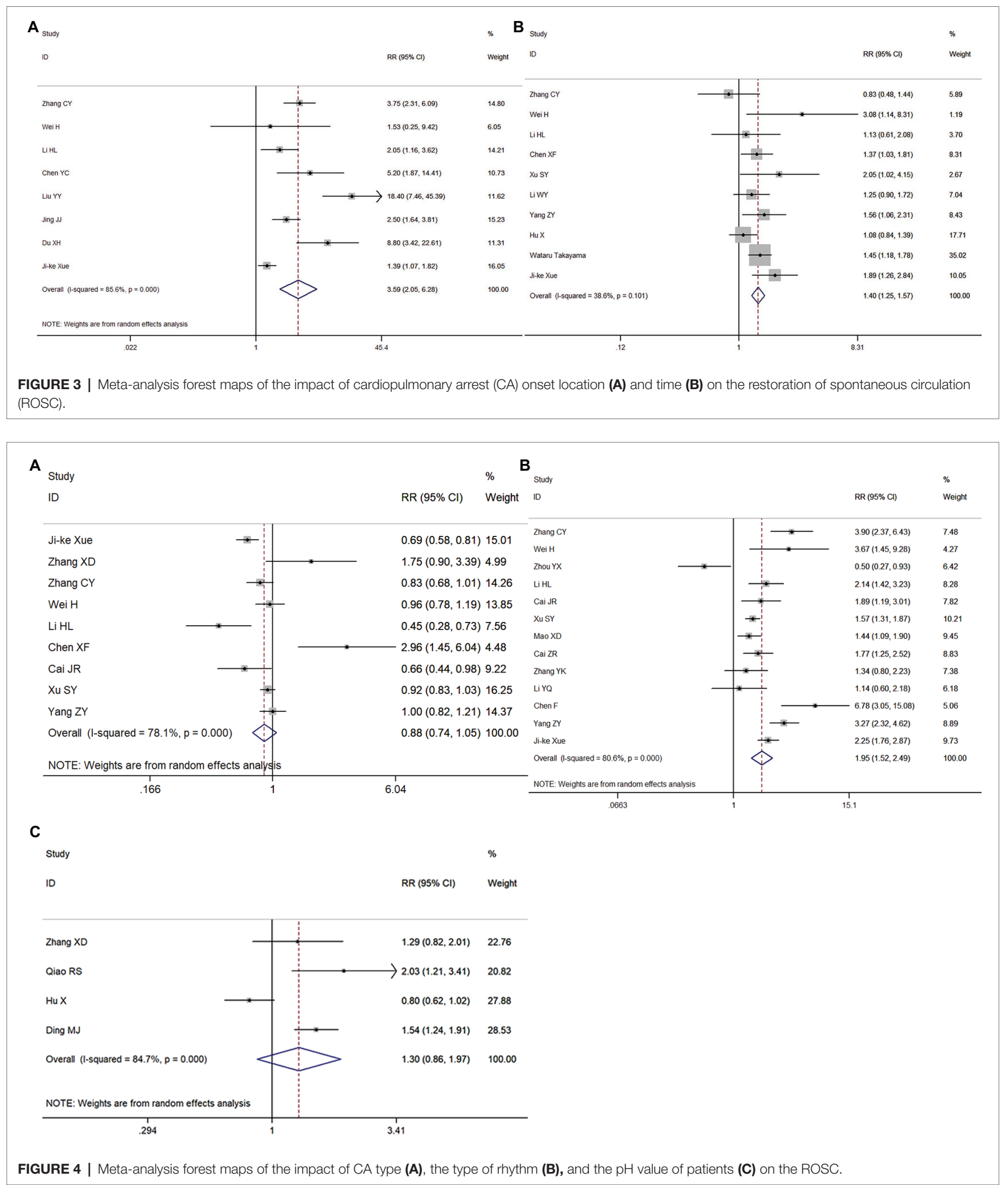

RR for the ROSC in CA patients with shockable rhythms was 1.95 (95\% CI $=1.52-2.49, p<0.001$; Figure $4 \mathrm{~B}$ ). Finally, the RR for the ROSC in patients with $\mathrm{pH}>7.0$ was $1.26(95 \%$
$\mathrm{CI}=0.75-2.11, p=0.38)$ compared with patients with $\mathrm{pH}<7.0$ (Figure 4C). Therefore, only a shockable rhythm was related to a successful ROSC. 


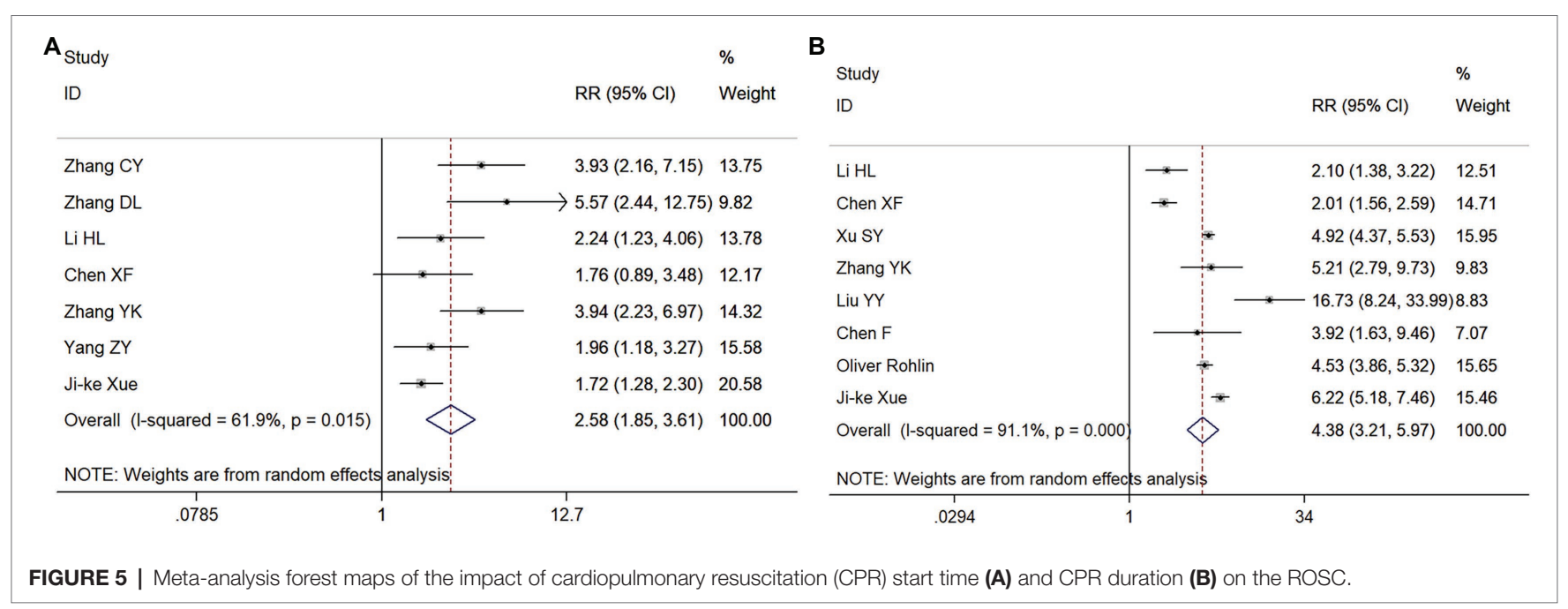

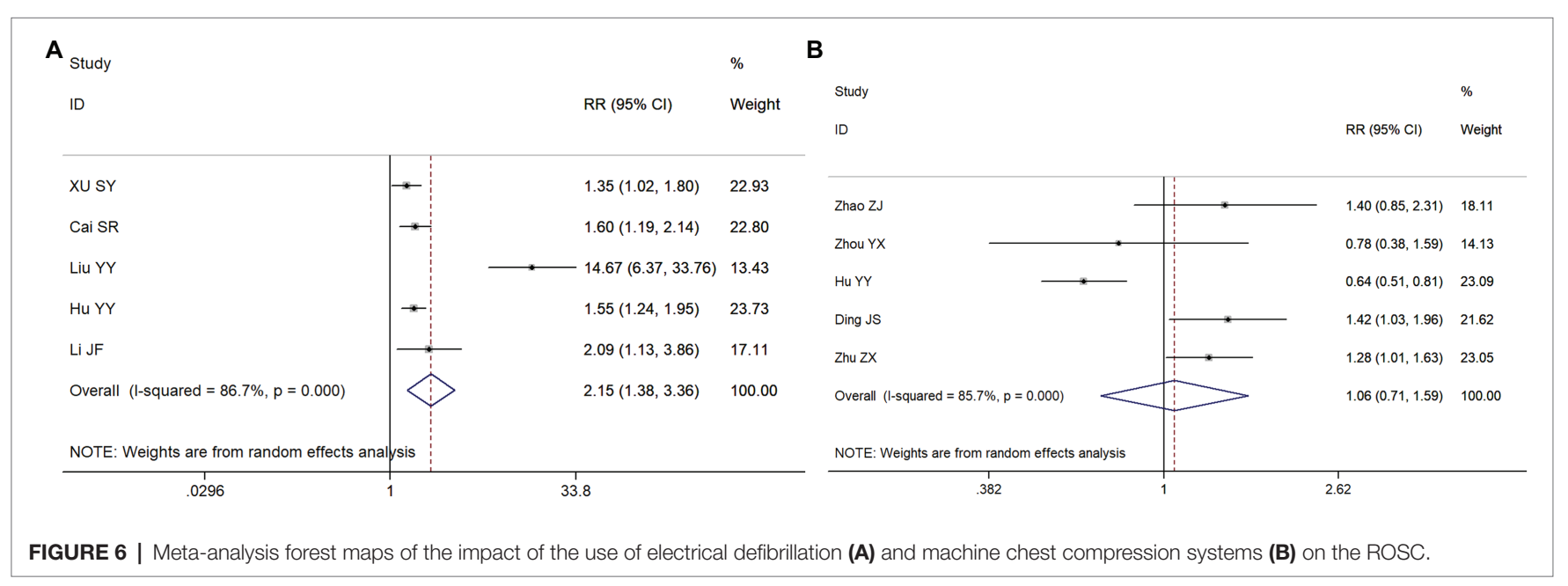

\section{Meta-Analysis of the Effect of CPR Start Time and Duration on the ROSC}

Seven and eight articles, respectively, were included in these meta-analyses. Compared with a CPR start time $>5 \mathrm{~min}$, the $\mathrm{RR}$ for the ROSC in patients with a CPR start time $\leq 5 \mathrm{~min}$ was 2.58 (95\% $\mathrm{CI}=1.85-3.61, p<0.001$; Figure $5 \mathrm{~A})$; the $\mathrm{RR}$ for the ROSC in patients with a CPR duration $\leq 15 \mathrm{~min}$ was 4.38 (95\% CI $=3.21-5.97, p<0.001)$, compared with a $\mathrm{CPR}$ duration $>15 \mathrm{~min}$ (Figure 5B). Therefore, both the start time and the duration of $\mathrm{CPR}$ were significantly associated with the ROSC in patients with $C A$.

\section{Meta-Analysis of the Effects of the Use of Electrical Defibrillation and CPR Machines on the ROSC}

Five independent studies were included in the meta-analyses to study the effect of the use of electric defibrillation and CPR machines on the ROSC in patients with CA. Compared with patients in whom electrical defibrillation was not used, the RR for the ROSC in patients receiving electrical defibrillation was 2.15 (95\% $\mathrm{CI}=1.38-3.36, p=0.01$; Figure 6A). However, compared with patients receiving manual chest compression, the RR for patients on whom a CPR machine was used was 1.06 (95\% CI $=0.71-1.59, p=0.784$; Figure 6B). Therefore, electric defibrillation therapy was positively associated with the ROSC in patients with CA, while machine chest compression systems had no significant influence on ROSC.

\section{Meta-Analysis of the Effects of the Cumulative Dose of Adrenaline and the Combined Use of Adrenaline and Vasopressin on the ROSC}

Fourteen and three studies, respectively, were included in these analyses. Compared with patients receiving $>5 \mathrm{mg}$ of adrenaline, the $\mathrm{RR}$ for the ROSC in patients receiving $\leq 5 \mathrm{mg}$ of adrenaline was $2.58(95 \% \mathrm{CI}=1.86-3.58, p<0.001$; Figure $7 \mathrm{~A})$, while the $\mathrm{RR}$ for the ROSC in patients treated with adrenaline and vasopressin was 1.08 (95\% $\mathrm{CI}=0.83-1.41, p=0.564)$, compared to those treated with adrenaline only (Figure $7 \mathbf{B}$ ). Therefore, the cumulative dose of adrenaline was negatively correlated with the ROSC in patients with $C A$. 

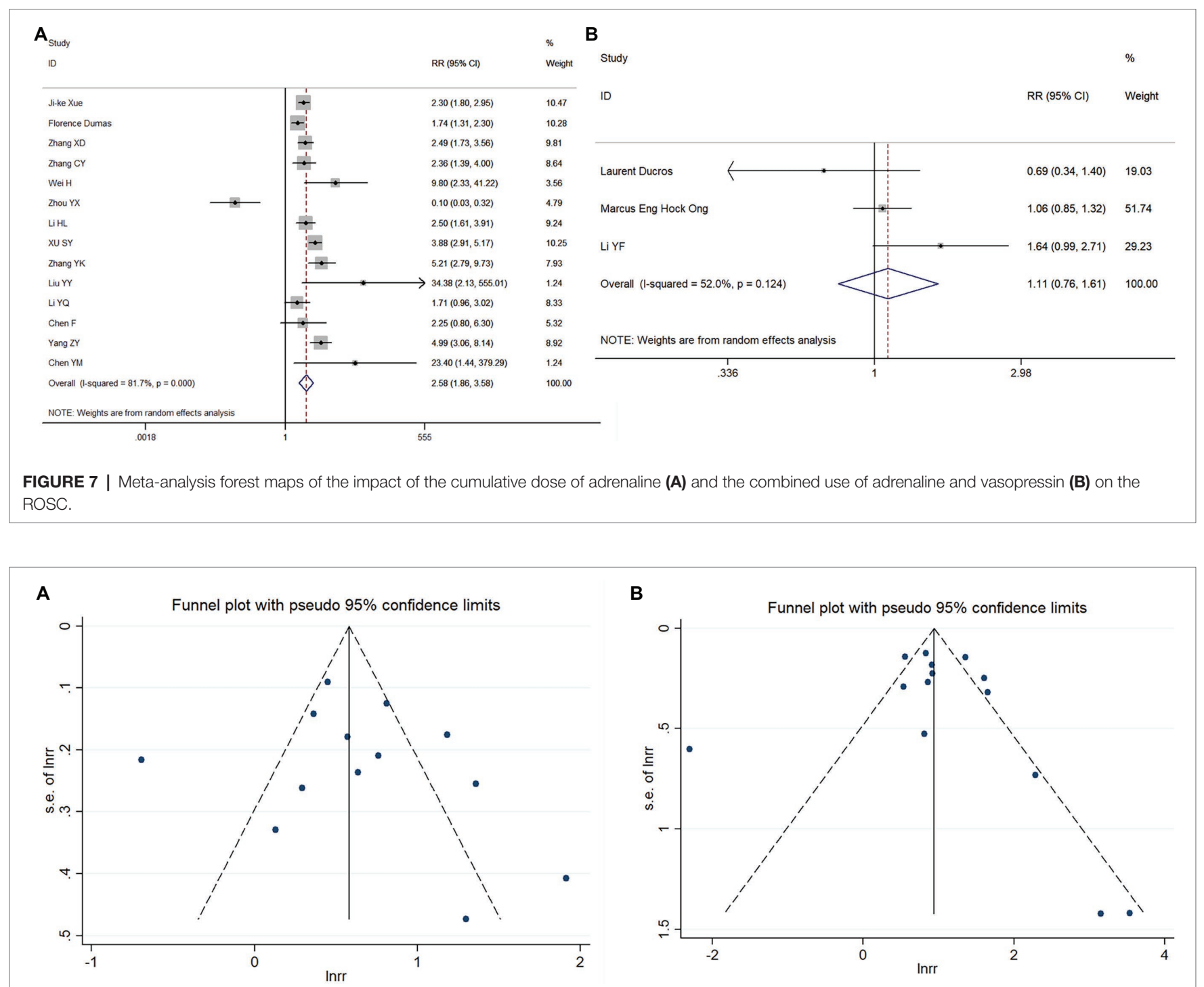

FIGURE 8 | Funnel plots of defibrillation rhythm (A) and the cumulative dose of adrenaline (B).

\section{Publication Bias and Sensitivity Analysis}

Egger's tests and funnel plot analyses were carried out for 11 indexes, which revealed no publication bias in any of them $(p>0.05)$. Some of the funnel diagrams are shown in Figures 8A,B.

\section{DISCUSSION}

Cardiac arrest is the most critical state seen in clinical practice. Although diagnosis and treatment have progressed in recent years, the prognosis for CA is still poor. Multiple factors impact the prognosis of the ROSC in patients with CA (Neumar et al., 2015). Medical staff must assess these so that the prognosis of patients can be more accurately judged and patients can receive the correct and timely treatment. This meta-analysis revealed that the location and time of onset of $\mathrm{CA}$, the type of cardiac rhythm, the start time of CPR, the use of external defibrillators defibrillators, and the cumulative dose of adrenaline significantly impacted the ROSC and may affect its success rate.

This meta-analysis revealed that the RRs for the ROSC in patients who suffered a CA during the day or in the hospital were significantly increased. Additionally, a considerable proportion of patients who suffer a CA at night or outside of the hospital may not receive CPR in time or in the correct manner. Furthermore, the ROSC in patients who received CPR within $5 \mathrm{~min}$ was also significantly increased. This suggests that the earlier CPR starts, the greater the likelihood of successful ROSC in patients with CA. Zhao reported that the smaller the rescue radius, and the shorter the $C A$ duration, the higher the rate of successful resuscitation (Zhao, 2017). A previous study also revealed that CPR given by eyewitnesses and electrical defibrillation were both associated with a 1-year improvement in neurological function and the reduction of all-cause mortality 
(Kragholm Wissenberg et al., 2017). Therefore, familiarization with $\mathrm{CPR}$ and rapid provision of $\mathrm{CPR}$ will greatly improve the success rate of treatment for patients with $C A$.

Whether CA is caused by heart disease and the $\mathrm{PH}$ value before treatment were not related to ROSC, but electrical defibrillation was given to patients with defibrillation rhythm or CA, suggesting that electrocardiography or electrocardiogram monitoring should be performed immediately if conditions permit to facilitate timely defibrillation. When the initial heart rhythm is ventricular fibrillation or ventricular tachycardia before electric defibrillation, the heart is in the condition of weak and irregular contraction. Therefore, the CPR in patients with ventricular fibrillation or ventricular tachycardia has a better performance. Where this is not possible, patients can be treated by electric defibrillation, which increases the probability of successful ROSC.

This meta-analysis showed that CPR of a shorter duration increased the probability of the ROSC in patients with $C A$. Similarly, a cumulative dose of adrenaline was negatively correlated with the ROSC. The longer duration of CPR will lead to more serious ischemia of vital organs, such as the heart, lung, and brain. Prolonged CPR may result in irreversible damage to these vital organs and result in poor patient prognosis even if ROSC occurs. Epinephrine has a more pronounced treatment benefit when given early in the resuscitation process, especially for non-shockable cardiac arrest (Soar and Berg, 2021). It is both a beta- and alpha-adrenergic receptor agonist. Its alpha effects cause peripheral vasoconstriction, which leads to increased blood flow in the central circulation, improving perfusion of the brain and heart. Epinephrine's beta-adrenergic effects increase heart rate, contractility, and automaticity. These potentially deleterious effects may lead to ventricular tachyarrhythmias and increased myocardial oxygen demand (Jung et al., 2018). Furthermore, the gradual accumulation of adrenaline leads to an increase in adverse reactions, such as visceral vasoconstriction, organ injury, and malignant arrhythmia.

The use of CPR machines does not increase the probability of successful ROSC compared with manual chest compression. Machine chest compression systems save on manpower (by decreasing or eliminating fatigue) and can automatically achieve the best balance between ventilation and compression. However, manual chest compression is simple to operate and does not require the use of other instruments, and it is not affected

\section{REFERENCES}

Cai, J. R. (2020). Clinical characteristics of cardiac arrest in emergency patients and influencing factors for success rate of cardiopulmonary resuscitation. J. Guangdong Med. Univ. 38, 50-53. doi: 10.3969/j.issn.1005-4057.2020.01.012

Cai, Z. S., Fang, W. G., Chen, H. H., Chen, R. H., Zhang, H. W., Zhu, L. M., et al. (2019). Analysis of influencing factor of in-hospital cardiac arrest prognosis. J. Trauma Emerg. 7, 16-21. doi: 10.16746/j.cnki.11-9332/r.2019.01.004

Chen, Y. C. (2019). Analysis of influencing factors and clinical characteristics of cardiopulmonary resuscitation success rate in patients with cardiac arrest. Chin. J. Clin. Rational Drug Use 12, 103-104. doi: 10.15887/j. cnki.13-1389/r.2019.02.070

Chen, Y. M., Dai, M. Y., Hao, W., Deng, G. Q., Deng, B. L., Feng, X. H., et al. (2016). Analysis of influence factors on cardiopulmonary resuscitation by factors such as time and location. Therefore, it is widely used in settings where a CPR machine cannot be installed. Furthermore, manual chest compression does not decrease the probability of ROSC in patients with $C A$.

This meta-analysis has some limitations. The quality of some of the papers included was low, and some of the factors were examined by only a few studies, which may have restricted the validity of the results. Therefore, the results of this metaanalysis should be treated with caution. The factors influencing the ROSC after CA must be confirmed by large-scale clinical trials to provide a practical and reliable reference basis for clinical treatment.

In summary, the location and time of onset of CA, the first monitored rhythm, the start time of CPR, the use of electric defibrillation, and the cumulative dose of adrenaline had significant effects on ROSC.

\section{DATA AVAILABILITY STATEMENT}

The original contributions presented in the study are included in the article/supplementary material; further inquiries can be directed to the corresponding authors.

\section{ETHICS STATEMENT}

Ethical review and approval was not required for the study on human participants in accordance with the local legislation and institutional requirements. Written informed consent for participation was not required for this study in accordance with the national legislation and the institutional requirements.

\section{AUTHOR CONTRIBUTIONS}

H-RA, J-QL, and X-LL: conception and design of the research. Y-RH, FC, and YM: acquisition of data. Y-RH and H-RA: analysis and interpretation of the data. Y-RH and C-YZ: statistical analysis. X-LL: obtaining financing. H-RA, Y-RH, and J-QL: writing of the manuscript. T-HW and X-LL: critical revision of the manuscript for intellectual content. All authors contributed to the article and approved the submitted version.

Chen, X. F., Ji, J. J., Sun, T., Zhao, H., and Liao, D. M. (2020). Analysis of associated factors of the prognosis after cardiopulmonary resuscitation in in-hospital cardiac arrest patients. Chin. J. Emerg. Resuscitat. Disaster Med. 15, 1366-1370. doi: 10.3969/j.issn.1673-6966.2020.12.010

Chen, F., and Luo, J. (2018). Analysis of factors influencing the effect of cardiopulmonary resuscitation before and in hospital. Modern Instruments 24, 55-57. doi: 10.11876/mimt201801022

Ding, M. J., and Xie, J. (2012). Analysis of prognostic factors in patients with cardiopulmonary resuscitation and spontaneous circulation recovery. J. Pract. Med. 28, 3956-3959. doi: 10.3969/j.issn.1006-5725.2012.23.039

Ding, J. S., and Zhang, T. (2018). Effects of bare-handed chest compression and mechanical chest compres-Sion on blood gas parameters and prognosis of patients 
during the initial stage of cardiopulmonary resuscitation. Chin. Mod. Doctor 56, 91-94.

Du, X.H. (2014). Analysis of factors affecting the prognosis of cardiac arrest patients and experience of cardiopulmonary resuscitation. Chinese Journal of Emergency Medicine, Collection of papers of the 13th Solicitation meeting and the sixth Youth Forum on Emergency Medicine.

Ducros, L., Vicaut, E., Soleil, C., Le Guen, M., Gueye, P., Poussant, T., et al. (2011). Effect of the addition of vasopressin or vasopressin plus nitroglycerin to epinephrine on arterial blood pressure during cardiopulmonary resuscitation in humans. J. Emerg. Med. 41, 453-459. doi: 10.1016/j.jemermed.2010.02.030

Dumas, F., Bougouin, W., Geri, G., Lamhaut, L., Bougle, A., Daviaud, F., et al. (2014). Is epinephrine during cardiac arrest associated with worse outcomes in resuscitated patients? J. Am. Coll. Cardiol. 64, 2360-2367. doi: 10.1016/j. jacc.2014.09.036

Hu, X., and Lu, Z. Y. (2016). Univariate analysis of pediatric in-hospital cardiopulmonary resuscitation. Chin. Pediatr. Emerg. Med. 2, 100-106. doi: 10.3760/cma.j.issn.1673-912.2016.02.007

Hu, Y. Y., Xu, J., Zhu, H. D., Zhang, G. X., Sun, F., Zhang, Y. Z., et al. (2018). Profile and outcome of cardiopulmonary resuscitation after sudden cardiac arrests in the emergency department: a multicenter prospective observational study. Chin. Crit. Care Med. 30, 234-239. doi: 10.3760/cma.j.issn.2095-4352.2018.03.009

Jing, J. J., He, G. H., and Yu, Z. F. (2017). Analysis of clinical prognosis and risk factors after cardiopulmonary resuscitation. J. Clin. Emerg. 18, 428-432. doi: 10.13201/j.issn.1009-5918.2017.06.007

Jung, J., Rice, J., and Bord, S. (2018). Rethinking the role of epinephrine in cardiac arrest: the PARAMEDIC2 trial. Ann. Transl. Med. 6:S129. doi: 10.21037/atm.2018.12.31

Kragholm Wissenberg, M., Mortensen, R. N., Hansen, S. M., Malta Hansen, C., Thorsteinsson, K., et al. (2017). Bystander efforts and 1-year outcomes in out-of-hospital cardia carrest. N. Engl. J. Med. 376, 1737-1747. doi: 10.1056/ NEJMoa1601891

Li, J. F. (2017). Clinical factors influencing the effect of pre-hospital emergency cardiopulmonary resuscitation. Med. Forum 21, 3089-3090. doi: 10.19435/ j.1672-1721.2017.23.044

Li, H. L. (2020). Logistic regression analysis of prognostic factors of cardiopulmonary resuscitation in emergency department. J. Med. Theor. Pract. 33, 3178-3180. doi: 10.19381/j.issn.1001-7585.2020.19.013

Li, Y. F., and Jia, Q. Y. (2020). Effect of antidiuretic hormone combined with epinephrine in the treatment of emergency cardiac arrest patients. Chin. Pract. Med. 15, 110-112. doi: 10.14163/j.cnki.11-5547/r.2020.02.050

Li, W. Y., Liu, S. F., Zhang, X. C., Zhao, L. L., Sun, Y. P., and Zhao, M. (2018a). Analysis on influencing factors of short-term prognosis of cardiopulmonary resuscitation among children with sudden cardiac arrest in pediatric intensive care unit. Matern. Child Health Care Chin. 33, 129-132.

Li, Y. Q., Qiu, Q. H., Zhang, X. B., Jiang, C. F., and Xing, B. (2018b). Analysis of factors influencing successful cardiopulmonary resuscitation in patients with cardiac arrest. Journal of Guangdong Medical University. 36, 600-602. doi: 10.3969/j.issn.1005-4057.2018.05.033

Liu, Y. Y. (2018). Influence factors of survival and discharge in emergency department patients undergoing cardiopulmonary resuscitation. Chin. Mod. Doctor 56, 105-107.

Mao, X.D. (2019). Analysis of Influencing Factors of Return of Spontaneous Circulation in-Hospital Adult Cardiac Arrest Patients. Ningxia Medical University. Available at: https://d.wanfangdata.com.cn/thesis/D02046163 (Accessed May 15, 2022).

Neumar, R. W., Shuster, M., Callaway, C. W., Gent, L. M., Atkins, D. L., Bhanji, F., et al. (2015). Part 1: executive summary: 2015 american heart association guidelines update for cardiopulmonary resuscitation and emergency cardiovascular care. Circulation 132, S315-S367. doi: 10.1161/CIR.0000000000000252

Ong, M. E., Tiah, L., Leong, B. S., Tan, E. C., Ong, V. Y., Tan, E. A., et al. (2012). A randomised, double-blind, multi-Centre trial comparing vasopressin and adrenaline in patients with cardiac arrest presenting to or in the emergency department. Resuscitation 83, 953-960. doi: 10.1016/j.resuscitation.2012.02.005

Qiao, R. S., Wu, X., Feng, X., Feng, N., Ni, W. D., and Zhao, X. Y. (2016). Logistic regression analysis on prognosis of patients with cardiopulmonary resuscitation return of spontaneous circulation. Progress Modern Biomed. 16, 6942-6958. doi: 10.13241/j.cnki.pmb.2016.35.039

Rohlin, O., Taeri, T., Netzereab, S., Ullemark, E., and Djärv, T. (2018). Duration of CPR and impact on 30-day survival after ROSC for in-hospital cardiac arrest-A Swedish cohort study. Resuscitation 132, 1-5. doi: 10.1016/j.resuscitation.2018.08.017
Soar, J., and Berg, K. M. (2021). Early epinephrine administration for cardiac arrest. JAMA Netw. Open 4:e2120725. doi: 10.1001/jamanetworkopen.2021.20725

Takayama, W., Endo, A., Koguchi, H., Murata, K., and Otomo, Y. (2019). Differences in durations, adverse events, and outcomes of in-hospital cardiopulmonary resuscitation between day-time and night-time: An observational cohort study. Resuscitation 137, 14-20. doi: 10.1016/j.resuscitation.2019.01.023

Tang, Z. R., He, Y. Q., and Guo, S. B. (2017). Research progress of cardiopulmonary resuscitation in 2016. Chin. J. Crit. Care Med. 37, 11-14. doi: 10.3969/j. issn.1002-1949.2017.01.003

Wei, H. (2021). Analysis of factors related to prognosis of emergency cardiopulmonary resuscitation. Clin. Res. Pract 6, 27-29. doi: 10.19347/j. cnki.2096-1413.202112010

Xu, S. Y., Zhu, H. D., and Yu, X. Z. (2019). The relationship between the outcome of cardiopulmonary resuscitation and the dosage of epinephrine in emergency department. Chin. J. Crit. Care Med. 39, 538-541. doi: 10.3969/j. issn.1002-1949.2019.06.003

Xue, J. K., Leng, Q. Y., Gao, Y. Z., Chen, S. Q., Li, Z. P., Li, H. P., et al. (2013). Factors influencing outcomes after cardiopulmonary resuscitation in emergency department. World J Emerg Med 4, 183-189. doi: 10.5847/wje m.j.issn.1920-8642.2013.03.005

Yang, Z. Y., Huang, T. B., and Zhang, G. Y. (2016). Prognosis of emergency cardiopulmonary resuscitation and its influencing factors. J. Chongqing Med. Univ. 41, 1234-1238. doi: 10.13406/j.cnki.cyxb.001100

Zhang, T. L. (2020). Study on the characteristics and success-related factors of cardiopulmonary resuscitation in emergency elderly patients. Chin. Foreign Med. Treat. 39, 1-4. doi: 10.16662/j.cnki.1674-0742.2020.07.001

Zhang, Y. K., Cui, X. P., Zhuang, J. Y., Sun, D., Xiao, Z., Huang, R. H., et al. (2018). Multiple factors analysis of the effect of cardiopulmonary resuscitation on cardiac arrest. Med. Innovat. Chin. 15, 97-100. doi: 10.3969/j. issn.1674-4985.2018.11.025

Zhang, X. D., Luo, L., and Xiang, T. (2021a). Analysis of influence factors for mechanical compressions on return of spontaneous circulation and prognosis in patients with cardiac arrest. Adv. Cardiovasc. Dis. 42, 737-758. doi: 10.16806/j.cnki.issn.1004-3934.2021.08.016

Zhang, C. Y., Meng, Y., Chi, F., Liang, J. Q., An, H. R., and Li, X. L. (2021b). Multiple factors analysis on the spontaneous circulation recovery after cardiopulmonary resuscitation in emergency department. Heibei Med. J. 43, 1009-1017. doi: 10.3969/j.issn.1002-7386.2021.07.010

Zhao, F. T. (2017). Retrospective analysis of related factors affecting the success rate of pre hospital cardiopulmonary resuscitation. Chin. Pract. Med. 12, 94-96. doi: 10.14163/j.cnki.11-5547/r.2017.10.043

Zhao, Z. J., Bai, W. M., and Xu, L. J. (2021). Effects of different cardiopulmonary resuscitation schemes on resuscitation success rate,blood gas analysis and blood indexes in patients with cardiac and respiratory arrest. J. Med. Forum $42,18-21$.

Zhou, Y. X., Han, W. W., and Song, D. D. (2020). Factors affecting autonomic circulation and prognosis after cardiopulmonary resuscitation in patients with cardiac arrest. J. Electrocardiol. Circulat. 39, 251-255. doi: 10.12124/j. issn.2095-3933.2020.3.2020-3986

Zhu, Z. X., Chen, S. J., Lin, W. W., Zhu, J. F., and Xu, Z. W. (2016). Study on the clinical effect of cardiopulmonary resuscitation machine and unarmed cardiopulmonary resuscitation. Prevent. Treat. Cardiovasc. Dis. 8, 4-6.

Conflict of Interest: The authors declare that the research was conducted in the absence of any commercial or financial relationships that could be construed as a potential conflict of interest.

Publisher's Note: All claims expressed in this article are solely those of the authors and do not necessarily represent those of their affiliated organizations, or those of the publisher, the editors and the reviewers. Any product that may be evaluated in this article, or claim that may be made by its manufacturer, is not guaranteed or endorsed by the publisher.

Copyright $\odot 2022$ An, Han, Wang, Chi, Meng, Zhang, Liang and Li. This is an open-access article distributed under the terms of the Creative Commons Attribution License (CC BY). The use, distribution or reproduction in other forums is permitted, provided the original author(s) and the copyright owner(s) are credited and that the original publication in this journal is cited, in accordance with accepted academic practice. No use, distribution or reproduction is permitted which does not comply with these terms. 